
\title{
$\begin{array}{ll}\text { Research Square } & \text { They should not be considered conclusive, used to inform clinical practice, } \\ \text { or referenced by the media as validated information. }\end{array}$ \\ KIF23 Predict Immune Infiltration and Overall Survival in Gastric Cancer
}

\section{Maoshu Bai}

Dazhou Integrated TCM and West Medcine Hospital

Xin Liu ( $\square$ liuxinkm@126.com)

The Third Affiliated Hospital of Kunming Medical University

\section{Research Article}

Keywords: Kinesin family member 23, immune infiltration, gastric cancer, prognosis, biomarker, TCGA, GEO.

Posted Date: January 11th, 2022

DOI: https://doi.org/10.21203/rs.3.rs-1222170/v1

License: (a) This work is licensed under a Creative Commons Attribution 4.0 International License. Read Full License 


\section{Abstract}

\section{Background}

Kinesin family member 23 (KIF23), an index of tumor proliferation, can serve as a prognostic marker in numerous tumors. However, the relationship between KIF23 expression and immune infiltration and the diagnostic value of KIF23 remain unclear in GC (gastric cancer). This study aimed to explored the prognosis value of KIF23 and its interactions with tumor-infiltrating immune cells in GC by bioinformatics analysis.

\section{Results}

The relationship between clinicopathologic features and KIF23 expression was also analyzed using the Wilcoxon ranksum test and logistic regression. And the expression level of KIF23 was validated by IHC and GEO databases, which was consistent with informatics results. Receiver operating characteristic (ROC) curves were generated to evaluate the value of KIF23 as a binary classifier using the area under the curve (AUC value). High expression of KIF23 was significantly associated with longer overall survival and progression-free survival in GC. The mutations of KIF23 in GC were analyzed using cBioPortal and the Catalogue of Somatic Mutations in Cancer database. Enrichment analysis of co-expressed genes and KIF23 analysis was performed using LinkedOmics. By using STRING and GeneMANIA databases, we investigated the protein-coding genes related to KIF23 and its co-expression genes in GC tissues. Then, the relationship between KIF23 expression and immune infiltration in GC was investigated using Timer and GEPIA. We found that KIF23 might be used as a potential prognosis biomarker in GC. Subsequently, KIF23 expression level was correlated with the infiltration levels of $\mathrm{CD} 8^{+} \mathrm{T}$ cells, macrophages, neutrophils, and more obviously with $\mathrm{B}$ cells and dendritic cells. In addition, KIF23 expression was significantly associated with T cell exhaustion (CTLA-4 and GZMB) KIF23 expression showed correlations with the infiltration of diverse immune markers in GC.

\section{Conclusion}

Our findings suggest KIF23 can serve as a marker for immune infiltration and prognosis in GC.

\section{Background}

Gastric cancer (GC) is the most frequently diagnosed malignant tumor and the third leading cause of cancer-related deaths globally $[1,2]$. Without specific symptoms in the early stage, GC is often diagnosed in the advanced stage during which no satisfactory therapy is available[3]. Thus, new molecular targets should be explored to reform current GC treatments. Immunotherapy, usually based on programmed death-1 (PD-1), cytotoxic T lymphocyte-correlated antigen 4 (CTLA4) and programmed death ligand-1 (PD-L1), has shown great therapeutic potential for various cancers, such as lung cancer and renal cancer[4]. However, anti-CTLA4 is lowly sensitive to GC[5]. Anti-PD-1 and anti-PD-L1 only trigger weak responses in advanced GC[6-8]. Tumor-infiltrating lymphocytes can mark tumor prognosis. Infiltration of tumorassociated macrophages (TAMs), tumor-infiltrating neutrophils (TINs) and neutrophils is closely related to the efficacy of chemotherapy and immunotherapy $[9,10]$. These evidences provide a possibility of developing new immunotherapy targets for GC.

Kinesin superfamily (KIF), a class of motor proteins mainly found in eukaryotic cells and encoded by more than 40 genes, participate in a variety of cell biological processes, such as microtubule movement, spindle formation, mitosis, axon extension and cell material exchange $[11,12]$. The overexpression of KIF members is closely implicated in the development of many tumors, such as lung cancer, breast cancer and liver cancer [11]. Kinesin family member 23 (KIF23) acts in the separation of cytoplasm during mitosis [13] and activation of Wnt/ $\beta$-catenin signaling pathway in GC [14]. KIF23 is closely related to immune infiltration in ovarian cancer [15]. In lung adenocarcinoma, LINC00337 may 
up-regulate the expression of PBK and KIF23 through competitively binding to has-mir-373 and has-mir-519d [16]. Although previous studies have confirmed the high expression of KIF23 in GC [17], the biology function and immunerelated mechanism of KIF23 in mechanism remain unclear.

The aim of this study was study the relation between KIF23 immune infiltration and overall survival by using bioinformatics analysis in gastric cancer and explored the contributes of KIF23 to the molecular typing of gastric cancer.

\section{Results}

\section{Expression and diagnostic value of KIF23 in GC patients}

The KIF23 expression level in tumor tissues was significantly higher than that in normal tissues $(P<0.001 ;$ Figure $1 \mathrm{~A})$, and also higher in tumor tissues than in paired normal tissues $(P<0.001$; Figure 1B). To evaluate the diagnostic performance of KIF23 in GC, we conducted ROC curve analyses. The ROC analysis of TCGA-STAD revealed significant diagnostic accuracy with AUC=0.958 (95\% Cl 0.937-0.978) (Fig.2A). Thus, KIF23 had potential to be a novel diagnostic biomarker for GC.

\section{Verification of KIF23 expression and diagnostic value in GC}

To validate the protein level of KIF23 in GC, we performed immunohistochemistry and found that the expression of KIF23 was elevated in GC tissues (Fig 3) compared with that in adjacent normal tissues.According to the KIF23 IHC staining, $20 \%$ (6/30) of adjacent GC tissues showed low expression of KIF23, while 3.33\% (29/30) of GC tissues showed high expression of KIF23. The profile of KIF23 mRNA expression in GC and normal gastric tissues was analyzed based on GEPIA ( $P<0.05$; Fig 1D). Finally, GSE2685 from the GEO databases was analyzed to verify the expression of KIF23 in GC. The expression of KIF23 was higher in the tumor tissues compared to that in normal tissues (Fig 1C). ROC curves were constructed to evaluate the diagnostic value of KIF23 for GC. The area under the ROC curve of GSE2685 was 0.86793 (Fig 2B).

\section{Associations of KIF23 expression level with clinicopathological variables}

Clinicopathological characteristics of the GC patients are listed in Table 1. As Table 1 showed, KIF23 expression was remarkably positively associated with age $(P=0.004)$, histological type $(P=0.006), H$ pylori infection $(P=0.030)$. No significant difference in KIF23 mRNA level was found in patients with pathological T stage $(P=0.756)$, pathological $N$ stage $(P=0.904)$, pathological $M$ stage gender $(P=0.626)$, pathological stage $(P=0.356)$, primary therapyoutcome $(P=0.635)$, gender $(P=0.776)$, residual tumor $(P=0.777)$ and histologic grade $(P=0.129)$.

\section{KIF23 expression in the stratified GC population}

KIF23 expression was significantly correlated with OS and progress free interval (PFS) in GC patients (Fig.2C-D). Next, we analyzed the prognostic value of KIF23 through Kaplan-Meier plotter database. Notably, higher KIF23 expression was still correlated to better OS and PFS in GC (Supplementary Figure1). The results showed that higher KIF23 mRNA expression was significantly correlated with a longer prognosis.

\section{Mutations of KIF23 in GC}

The mutation frequency of KIF23 in GC was evaluated in the cBioPortal database. Five datasets (MSK, AMC, INSERM, RIKEN and TCGA-PanCancer Atlas), which included 1000 samples, were selected for analysis [18, 19]. The somatic mutation frequency of KIF23 in GC was 1.8\%, which mainly consisted of missense mutations (Fig. 4A). This mutation 
frequency was relatively low, only 18 in 1000 samples. Furthermore, the mutation types of KIF23 were further evaluated in another database, COSMIC. For clarity, two pie charts of the mutation types are shown in Fig. 4. Missense substitutions occurred in approximately $42.39 \%$ of the samples, synonymous substitutions occurred in $11.11 \%$ of the samples, and frameshift deletions occurred in $11.36 \%$ of the samples (Fig. 4B). The substitution mutations mainly occurred at G>A (27.01\%), followed by C > T (24.82\%), C > A (10.22\%) and G > T (9.85\%) (Figure 4C).

Gene co-expression and hub gene analysis in GC

To further validate the biological activities of KIF23 in GC, the KIF23-related DEGs were evaluated in GC. The volcano map identified KIF23-related DEGs, with positively related genes on the right of the plot and negatively related genes on the left of the plot (Fig. 5C). Additionally, the heatmaps of the top 10 positively related genes were BUB1B, BUB1, PRC1, ARHGAP11A, C15orf23囚TPX2, CCNB2, FANCI, NUSAP1 and ZWILCH (Fig. 5A). The top 10 negatively related genes identified were LTC4S, MARCH2, GYPC, FXYD1, CLEC3B, CBX7, JAM2, PBXIP1, GFRA1 and MFAP4 (Fig 5B). To determine the relationship of the top 100 positively related genes of KIF23 in GC, a PPI network was established. As shown in Fig. 4D, frequent interaction among the top 100 genes had close relationships with KIF23 expression. After calculating by degree using Cystoscope software, we obtained ten hub genes that revealed the closest relationships. The ten hub genes were BUB1, CDK1, CCNA2, CDCA8, CCNB1, CCNB2, KIF11, KIF2C, NCAPG and UBE2IR (Fig. 5E). Furthermore, Gene-MANIA tools were used to analyze the interaction between KIF23 and protein-coding genes mentioned earlier. Fig. 5F illustrates the results of the analysis.

\section{Functional enrichment analysis and predicted signaling pathways}

To better understand the functional implication of KIF23 in GC based on the top 100 significantly related genes, GO enrichment analysis was performed using the Cluster Profile package. GO results (Fig. 6A) revealed top four significant biological processes (BP), top four cellular components (CC), and top four molecular functions (MF). The results showed these co-expression genes were mainly involved in tubulin binding, microtubule and regulation of cell division in biological process, cellular component and molecular function, respectively. Moreover, according to KEGG analysis, the results of KIF23 related co-expression gene were mainly involved in the cell cycle, oocyte meiosis and secretion and DNA replication pathways (Fig. 6B). The results of KEGG pathway analysis showed that the functions of KIF23 and its neighboring genes were mainly enriched in the cell cycle, DNA replication, fanconi anemia pathway and homologous recombination (Fig. 6C). These results demonstrated that KIF23 has a wide range of effects on the genes and pathways involved in cell cycle.

\section{Correlation between KIF23 expression and immune microenvironment in GC}

In TIMER database, KIF23 expression was related with the purity in 16 cancer types, B cell infiltration in 24 cancer types, CD8+ T cell infiltration in 17 cancer types, CD4+ T cell infiltration in 17 cancer types, macrophage infiltration in 21 cancer types, neutrophil infiltration in 24 cancer types, and dendritic cell infiltration in 21 cancer types (Fig.7 and Supplementary Figure 2).

We next found that KIF23 was correlated with the infiltration of six types of immune cells (B cell, CD8+ T cells, CD4+ T cells, macrophage, neutrophil, DCs) in GC and ESCA (Fig. 7A). To be specific, KIF23 expression was negatively related to the infiltration of $B$ cells $(r=-0.162, P=1.79 E-03), C D 8+T$ cells $(r=-0.236, P=4.62 E-06), C D 4+T$ cells $(r=-0.218, P=2.57 E-05)$, macrophages $(r=-0.324, P=1.65 E-10)$, neutrophils $(r=-0.132, P=1.09 E-02)$, and dendritic cells $(r=-0.233, P=5.63 E-06)$ in GC. However, KIF23 expression was not significantly related to the infiltration of B cells $(r=0.044, P=5.57 E-01), C D 8+T$ cells $(r=-0.046, P=5.39 E-01), C D 4+T$ cells $(r=-0.139, P=6.42 E-02)$ and macrophages $(r=0.034, P=6.47 E-01)$, except neutrophils ( $r=-0.191, P=1.02 E-02)$ and dendritic cells $(r=-0.196, P=8.27 E-03)$ in ESCA. These findings suggested that KIF23 expression was correlated with immune infiltration in GC. 
We further compared the infiltration level in GC and ESCA with different somatic copy number alterations (SCNA) in KIF23 (Fig.7B). In ESCA, CD8+ T cell was the main infiltrating immune cell in the arm-level deletion state of KIF23 gene, while $B$ cell was the main infiltrating immune cell in the arm-level gain state (all $P<0.05$ ). In GC, B cell, CD8+ T cell, CD4+ T cell, macrophage, neutrophil and dendritic cell were the main infiltrating immune cells in the arm-level deletion state of KIF23 gene, while CD8+ T cell, CD4+ T cell, neutrophil and dendritic cell were the main infiltrating immune cells in the arm-level gain state (all $\mathrm{P}<0.05$ ). B cell and CD8+ T cell were the main infiltrating immune cells in the high amplication state of KIF23 gene (all $\mathrm{P}<0.05)$.

\section{Correlation analysis between KIF23 expression and immune marker sets}

We analyzed the correlations between KIF23 and marker genes of different immune cells, including CD8 ${ }^{+} \mathrm{T}$ cells, T cells(general), B cells, monocytes, TAMs, M1 macrophages, M2 macrophages, neutrophils, NK cells and DCs in GC, using esophageal carcinoma (ESCA) as the control (Table 2 and Fig.8-9). Moreover, we analyzed the levels of functional T cells, namely, Th1 cells, Th2 cells, Tfh cells, Th17 cells, and (regulatory)Tregs, as well as exhausted T cells. After adjustment for purity, the results revealed the KIF23 expression was significantly correlated with the expression of markers of most immune cells and T cells in ESCA and GC. (Table 3). TIMER and GEPIA analyses showed that KIF23 expression in GC tissue was significantly correlated with the expression of marker genes in B cells, monocytes, TAMs, neutrophils, DCs, T-helper, Tfh, Treg and exhausted T cells, but not in ESCA (Fig 8-9and Table 3).

KIF23 expression showed significant correlation with the expression of markers of immune cells: B cell marker, CD19 $(r=-0.168 ; P=1.03 e-03), C D 79 A(r=-0.276 ; P=4.59 e-08)$; monocyte marker, CD115 ( $r=-0.136 ; P=8.21 e-03)$; TAM marker, CCL2 ( $r=-0.216 ; P=2.22 e-05) ; M 1$ macrophage marker, iNOS ( $r=0.18 ; P=4.38 e-04) ; M 2$ macrophage marker, MS4A4A $(r=-0.127 ; P=1.35 e-02)$; neutrophil markers, CD66b ( $r=0.175 ; P=6.16 e-04)$ and CCR7 ( $r=-0.232 ; P=5.02 e-06)$; NK cell markers, KIR2DL1( $r=0.118 ; P=2.11 e-02), K I R 2 D L 3(r=0.121 ; P=1.81 e-02)$ and KIR2DL4( $r=0.213 ; P=2.95 e-05)$; DC markers, BDCA-1 ( $r=-0.375, P=3.97 E-14), B D C A-4(r=-0.3, P=2.69 E-09)$.

Significant correlation existed between KIF23 and marker genes of exhausted Treg and T cells: Th1 marker, STAT1 $(r=0.4, P=1.8 E-17)$ and IFN- $\gamma(r=0.19, P=8 E-05)$; Th2 marker, GATA3( $r=-0.16, P=1.4 E-03)$; Tfh marker, BCL6( $r=-0.1$, $\mathrm{P}=0.038)$ and IL21 $(r=0.067, \mathrm{P}=0.18)$; Th17 marker, IL17A ( $r=0.19, \mathrm{P}=8.1 \mathrm{E}-05)$; Treg marker, TGF $\beta(r=-0.13, \mathrm{P}=8.7 \mathrm{E}-03)$. Notably, exhausted T cell markers CTLA-4 $(r=0.16, P=8.4 E-04)$ and GZMB $(r=0.16, P=1.5 E-03)$ had a moderate correlation with KIF23 expression, suggesting that high KIF23 expression plays an important role in CTLA4-mediated T cell exhaustion. Therefore, these findings confirm that KIF23 is specifically correlated with immune infiltrating cells inGC.

\section{Discussion}

KIF23 gene, located on chromosome ch15q23, was discovered in the 1992 [20]. KIF23 is involved in cell proliferation and differentiation [21], and abnormally expressed in glioma [22], breast cancer [23] and non-small cell lung cancer [24, 25].

In this study, the expression level of KIF23 was high in GC tissues compared to that in adjacent normal tissues by several public databases. Recent studies suggested that KIF23 was highly expressed in GC [14, 17], and related to its poor prognosis [17]. Herein, we found that the profile of KIF23 expression in GC tissue was consistent across different databases. Consistently, in our study, we also validated that the expression of KIF23 was highly expressed in GC tissues compared to adjacent tissues, whereby KIF23 expression was an independent predictor of diagnostic in GC. On the contrary, we found that overexpressed KIF23 was related to longer OS and PFS. This may be due to different stages, grade of invasiveness and lymph node metastasis of GC were included in the study. We found that the expression of 
KIF23 was increased in GC tissues compared with that in normal tissues in TCGA cohort and GEO cohort and suggested that KIF23 might be used as a potential diagnostic biomarker in GC.

Kaplan-Meier plotter database incorporates the mRNA expression data of more than 50000 genes and more than 10000 cancer samples, half of which are from GC patients. Our Kaplan-Meier plotter database analysis showed that the high expression of KIF23 was related to the good prognosis of GC patients, suggesting that KIF23 may inhibit the growth of GC, and can be used to mark its prognosis. In addition, HER-2 is linked to GC prognosis [26].

Although KIF23 is a transformation factor, we still do not know the mechanism through which it regulates GC. In general, we found several mutational expressional alterations of KIF23 in GC, mainly missense substitutions. However, the mutation frequency was relatively low (only $1.8 \%$ ), and we failed to find a relation between these mutations and prognosis. More researches are needed to illustrate the clinical significance of these mutations. First, we analyzed the protein-coding genes related to KIF23 and its co-expression genes in GC tissues. The top 10 protein-coding genes positively correlated with KIF23 were BUB1B, BUB1, PRC1, ARHGAP11A, C15orf23, TPX2, CCNB2, FANCI, NUSAP1 and Z[14]WILCH. On the other hand, the top 10 negatively correlated genes included LTC4S, MARCH2, GYPC, FXYD1, CLEC3B, CBX7, JAM2, PBXIP1区GFRA1 and MFAP4. Furthermore, STRING and Gene MANIA databases illustrated the protein interaction between KIF23 and other partners. The proteins related to KIF23 perform following biological functions: cell cycle, mitosis, DNA damage response, cell proliferation, and aging.

Thereafter, GO and KEGG pathway analysis revealed that an up-regulated expression of KIF23 was primarily related to cell cycle, and DNA replication, oocyte meiosis. Previous studies have also reported that KIF23 is associated with cell proliferation [13], and it also regulates cell cycle in many types of cancers [14]. A large amount of evidence shows that Wnt/ $\beta$-catenin signaling plays an important role in the proliferation, migration, invasion and angiogenesis of cancer cells $[27,28]$. Specifically, Wnt/ $\beta$-catenin signaling can promote cancer development by regulating the tumor-immune cycle in tumor microenvironment, including T cell infiltration, dendritic cells, T cells and tumor cells [29, 30]. The Wnt signaling pathway has been demonstrated to be one of the most frequently pathways in GC and controls several fundamental cell functions, including proliferation, differentiation, migration, and stemness [31]. KIF23 promotes GC cell proliferation by activating the Wnt/ $\beta$-catenin signaling pathway. Cell cycle proteins in malignant cells have attracted considerable interest as potential targets for cancer therapy. Further studies could help verify which processes and pathways KIF23 functions through in GC in vivo. Our results help to advance the understanding of the biological functions of KIF23 which make its overexpression so detrimental in GC.

We further found that KIF23 expression changed with the expression of marker genes of immune cells, thus highlighting the possible role of KIF23 in immunological regulation in GC. As the tumor develops, immune cells migrate from the blood into tumor tissue, a process closely related to clinical outcomes. TIICs are an independent predictor of sentinel lymph node status and cancer survival [32]. TIICs exert an anticancer effect relying on immune cancer escape mechanism. Nevertheless, it remains challenging to confirm the interaction between immune cells and tumor cells using genomics analysis.

This study also found that the expression of KIF23 was correlated with the degree of immune infiltration in multiple cancer types, particularly in GC. We found that KIF23 expression was moderately and positively correlated with the degree of macrophage infiltration, and weakly and positively correlated with that of B cell, CD8+, CD4+, DC and neutrophil in GC (Figure 7A). In addition, the correlation between KIF23 and immunological marker genes strongly suggests that in GC, KIF23 can control immune cell infiltration within the tumor micro-environment (TME). We observed a weak correlation between KIF23 and neutrophage markers, including NOS2 and CCR7 (Table 2). This suggests that KIF23 plays a role in regulating TAM polarization. Shu et al reviewed that target TAMs can achieve cancer 
immunotherapy [33], inhibiting the growth of tumors. TAMs have been widely deemed as a favorable condition for tumor development, including tumor cell growth, EMT, and immune suppression in TME.

We further found KIF23 level was correlated with markers of exhausted Treg cells and T cells in GC (CTLA4 and GZMB) (Table 2). This suggests that KIF23 can enhance Treg response to suppress T cell-mediated immunity. Furthermore, we found that KIF23 expression was correlated with that of multiple T cell markers (Th1, Th2, Tfh and Th17) in GC. This may correspond to the ability of KIF23 to regulate T cell responses in GC. Together, these results highlight the ability of KIF23 to regulate immune cell recruitment and activation in GC. In HCC $\otimes$ Pu et al. has investigated that KIF23 expression was correlated to immune cell infiltration, including B cells, CD8+T cells, CD4+T cells, monocytes, macrophages, neutrophils, and dendritic cells [34].

We further analyzed [35]the correlation between KIF23 and monocytes and TAMs markers in the GEPIA database. Correlation results were similar to those in TIMER (Table 3). These findings suggest that KIF23 may regulate macrophage polarization in GC and ESCA. KIF23 expression increased with the infiltration of DCs in GC and ESCA. DC markers, such as HLA-DPB1DBDCA-1(CD1C) and BDCA-4(NRP1), also showed significant correlations with KIF23 expression. These results further reveal a strong relationship between KIF23 and DCs infiltration. In addition, KIF23 expression displayed a positive correlation with TGFB1 expression in Treg cells in GC. DCs can promote tumor metastasis by increasing the levels of Treg cells and reducing CD8+T cell cytotoxicity [35]. Further studies should be organized to prove whether KIF23 can mediate DC activity and tumor metastasis.

Several limitations may challenge the results of this study. First, this study is based on data retrieved from published articles and public repositories. Hence, the quality of some original data may be not unsatisfied. Second, the quantity of samples in the databases is in consistent change. Third, the statistical methods used in database analysis may influence the interpretation of the study results. However, we obtained similar results from multiple databases, which upholds our conclusion. Furthermore, we have not conducted in vitro and animal experiments to confirm our findings.

These results are helpful to understand the biological role played by KIF23 in the development of GC. In future clinical practice, the expression of KIF23 in gastric adenocarcinoma tissue may be used to predict the diagnosis and the efficacy of immunotherapy of patients.

\section{Conclusion}

KIF23 is highly expressed in GC tissue and associated with a good prognosis. KIF23 expression changes with the infiltration of diverse immune markers. KIF23 may serve as a potential marker for diagnosis and treatment of GC.

\section{Methods}

\section{Collection of genetic data and expression analysis}

The Stomach Adenocarcinoma (STAD, or GC) dataset was downloaded from TCGA (https://portal.gdc.cancer.gov/) which included 32 samples of normal gastric tissue and 375 samples of GC tissue (Workflow Type: HTSeq-FPKM). The samples lacking corresponding clinical data were excluded from the analysis. Level-3 HTSeq-FPKM data were transformed into transcripts per million reads (TPM) for subsequent analyses. Then, the expression of KIF23 in normal gastric and GC tissues was demonstrated by Boxplots and a paired differential plot. Gene expression data were divided into a high expression group and a low expression group according to the median KIF23 expression level. Validation cohort GSE2685 was selected from the GEO database (https://www.ncbi.nlm.nih.gov/geo/). The median mRNA levels 
of KIF23 expression in GC tissue and normal gastric tissue were analyzed and plotted in GEPIA (https://gepia.cancerpku.cn/). In addition, GEPIA was also used to generate differential expression analysis and analyze their correlation to specific gene expression analysis.

\section{Diagnostic and prognostic value analysis}

ROC curves were plotted, and the area under the ROC curve was calculated using the ROCR package in R. The patients were divided into a high KIF23 expression group and a low KIF23 expression group according to the best matched value for the diagnostic analysis. We selected the datasets (GSE2685) from GEO and TCGA to access the diagnostic value of KIF23. The best cut-off value was derived using Cut-off Finder software based on an R routine which optimized the significance of the split between Kaplan-Meier (K-M) survival curves measured by the log-rank test [36]. The KaplanMeier Plotter (http://kmplot.com/analysis/) is an online tool to assess the survival of breast, lung, ovarian, and gastric cancer patients.

\section{Mutation analysis}

The mutation frequency of KIF23 in GC was evaluated using cBioPortal (http://www.cbiop ortal.org/). The mutation types of KIF23 in GC were further evaluated using the Catalogue of Somatic Mutations in Cancer (COSMIC) database (http://cancer.sanger.ac.uk).

\section{Gene co-expression and functional enrichment analysis}

The Function module of LinkedOmics (http://www.linkedomics.org/) was used to analyze mRNA sequencing data from 407 GC patients in TCGA. The result was presented as a volcano plot. The top 50 positively and negatively correlated genes were depicted by heatmaps. These genes were put into the GO and KEGG websites to obtain the enriched GO terms and significant KEGG pathways. In addition, these genes were selected to construct PPI network using both the STRING database (http://string-db.org). And, Cytoscape software (version 3.8.2) (https://cytoscape.org/) were used to determine hub genes and investigate the correlation between hub genes and KIF23 expression.

\section{Immune infiltration analysis}

TIMER is an online tool for systematic analysis of immune cell infiltration in various cancers (https://cistrome.shinyapps.io/timer/) [37]. We explored the expression of KIF23 in diverse cancer types, and the correlation of KIF23 expression with the abundance of TIICs, including B cells, CD4+ T cells, CD8+ T cells, neutrophils, macrophages, and dendritic cells. Correlation between gene expression and tumor purity was displayed on the left-most panel [38]. Lastly, we explored the correlations between KIF23 and gene markers of TIILs, including T cells(general), monocytes, CD8+ T cells, B cells, TAMs, M1 macrophages, M2 macrophages, neutrophils, natural killer (NK)cells, dendritic cells (DCs), T-helper 1 (Th1) cells, T-helper 2(Th2) cells, T-helper 17 (Th17) cells, Tregs, follicular helper T (Tfh) cells, and exhausted T cells. GEPIA was used to validate the gene correlation analysis in TIMER.

\section{Clinical samples and immunohistochemistry analysis}

Tissue microarray (TMA) of primary GC samples were purchased from Shanghai Outdo Biotech Co., Ltd. (Shanghai, China). HStmAde060PG-01 included 30 cases of gastric adenocarcinoma tissues and paired adjacent tumor tissues. Detailed clinical characteristics, including patient age and sex, tumor size, histologic differentiation, and TNM stage, were available with patients consent.

Immunohistochemical (IHC) staining was performed with the following steps. Formalin-fixed, paraffin-embedded tissue slides were dewaxed with xylene and rehydrated by a graded series of alcohols, followed by antigen retrieval and block 
with $5 \%$ BSA for $60 \mathrm{~min}$. Incubation was carried out at $4{ }^{\circ} \mathrm{C}$ overnight with primary antibodies. Primary antibodies included anti-KIF23 polyclonal antibody (1:200; Affinity). Immunohistochemical staining was performed according to the manufacturer's protocol to examine the expression level of KIF23 in GC and matched normal tissue. An KIF23 rabbit polyclonal antibody was purchased from Affinity Biosciences (DF2573; Affinity, American) and used at a dilution of 1:200. Two pathologists independently evaluated immunostaining of each tissue section in a double-blind manner. The immunoreactive score (IRS) $[39,40]$ for each slice was calculated by multiplying the staining intensity in four gradations ( 0 , negative; 1 , weak; 2 , moderate; 3 , strong) with the percentage of positive cells in five gradations $(0$, negative; $1,<10 \% ; 2,10 \%-50 \% ; 3,51 \%-80 \% ; 4,>80 \%)$. Each specimen was measured in three different magnification fields. IRS ranged from 0 to 12 , with IRS $>6$ indicating high KIF23 expression and IRS $\leq 6$ indicating low KIF23 expression. The study was approved by the Ethics Committee of Dazhou Integrated TCM and West Medcine Hospital.

\section{Statistical analysis}

All statistical analyses and plots were conducted using $\mathrm{R}$ (Version 3.6.3). Wilcoxon rank-sum test and Wilcoxon rank signed test were used to analyze the expression of KIF23 in non-paired samples and paired samples, respectively. Kruskal-Wallis test, Wilcoxon rank-sum test, and logistic regression evaluated relationships between clinical-pathologic features and KIF23 expression. Furthermore, ROC analysis and the frequently-used method for binary assessment were performed using the PROC package [41] to assess the effectiveness of KIF23 expression to discriminate GC from normal samples. The computed AUC value ranging from 0.5 to 0.1 indicates the discriminative potential from $50 \%$ to $100 \%$ [42]. Gene expression data from GEPIA databases were analyzed using the P-values. Survival curves were produced by the Kaplan-Meier plots database. The correlation between gene expression and TIIC infiltration was evaluated in the TIMER and GEPIA databases using Spearman's correlation analysis. P-value $<0.05$ was considered to be statistically significant. Statistical and graphical analyses were performed with GraphPad Prism, version 9.0 (GraphPad Software).

\section{Abbreviations}

KIF23: Kinesin family member 23

GEO: Gene expression omnibus

GO: Gene ontology

GC: Gastric cancer

KM: Kaplan-Meier

PPI: Protein-protein interaction

ROC: Receiver operating characteristic

TCGA: The Cancer Genome Atlas

TME: tumor micro-environment

TIICs: tumor-infiltrating immune cells

\section{Declarations}

\section{Ethics approval and consent to participate}


Not necessary

\section{Consent for publication}

Not applicable

\section{Availability of data and materials}

The raw data of this study are derived from the GEO data portal (https://www.ncbi.nlm.nih.gov/geo/),TCGA (https://portal.gdc.cancer.gov/), GEPIA (https://gepia.cancer-pku.cn/), GEPIA (https://gepia.cancer-pku.cn/), Cytoscape software (version 3.8.2) (https://cytoscape.org/), TIMER(https://cistrome.shinyapps.io/timer/), The Kaplan-Meier Plotter (http://kmplot.com/analysis/), which are publicly available databases.

\section{Competing interests}

The authors declare that there are no conflicts of interest.

\section{Funding}

This study was supported by grants from Sichuan Provincial Administration of Traditional Chinese Medicine (Grant no.2021MS547) and Yunnan provincial health science and technology program(Grant no. 2017NS201)

\section{Authors' contributions}

Maoshu Bai and Xin Liu designed the study, as well as wrote and corrected the article. All authors read and approved the final article.

\section{References}

1. Bray F, Ferlay J, Soerjomataram I, Siegel RL, Torre LA, Jemal A: Global cancer statistics 2018: GLOBOCAN estimates of incidence and mortality worldwide for 36 cancers in 185 countries. CA: a cancer journal for clinicians. 2018; 68(6):394-424.

2. Chen W, Zheng R, Baade PD, Zhang S, Zeng H, Bray F, Jemal A, Yu XQ, He J: Cancer statistics in China, 2015. CA: a cancer journal for clinicians. 2016; 66(2):115-32.

3. Ren J, Niu G, Wang X, Song T, Hu Z, Ke C: Overexpression of FNDC1 in Gastric Cancer and its Prognostic Significance. Journal of Cancer. 2018; 9(24):4586-95.

4. Osmani L, Askin F, Gabrielson E, Li QK: Current WHO guidelines and the critical role of immunohistochemical markers in the subclassification of non-small cell lung carcinoma (NSCLC): Moving from targeted therapy to immunotherapy. Seminars in cancer biology. 2018; 52(Pt 1):103-9.

5. Ralph C, Elkord E, Burt DJ, O'Dwyer JF, Austin EB, Stern PL, Hawkins RE, Thistlethwaite FC: Modulation of lymphocyte regulation for cancer therapy: a phase II trial of tremelimumab in advanced gastric and esophageal adenocarcinoma. Clinical cancer research : an official journal of the American Association for Cancer Research. 2010; 16(5):1662-72.

6. Overman MJ, McDermott R, Leach JL, Lonardi S, Lenz HJ, Morse MA, Desai J, Hill A, Axelson M, Moss RA et al: Nivolumab in patients with metastatic DNA mismatch repair-deficient or microsatellite instability-high colorectal cancer (CheckMate 142): an open-label, multicentre, phase 2 study. The Lancet Oncology. 2017; 18(9):1182-91.

7. Le DT, Durham JN, Smith KN, Wang H, Bartlett BR, Aulakh LK, Lu S, Kemberling H, Wilt C, Luber BS et al: Mismatch repair deficiency predicts response of solid tumors to PD-1 blockade. Science. 2017; 357(6349):409-13. 
8. Muro K, Chung HC, Shankaran V, Geva R, Catenacci D, Gupta S, Eder JP, Golan T, Le DT, Burtness B et al: Pembrolizumab for patients with PD-L1-positive advanced gastric cancer (KEYNOTE-012): a multicentre, openlabel, phase 1b trial. The Lancet Oncology. 2016; 17(6):717-26.

9. Waniczek D, Lorenc Z, Snietura M, Wesecki M, Kopec A, Muc-Wierzgon M: Tumor-Associated Macrophages and Regulatory T Cells Infiltration and the Clinical Outcome in Colorectal Cancer. Archivum immunologiae et therapiae experimentalis. 2017; 65(5):445-54.

10. Zhang H, Liu H, Shen Z, Lin C, Wang X, Qin J, Qin X, Xu J, Sun Y: Tumor-infiltrating Neutrophils is Prognostic and Predictive for Postoperative Adjuvant Chemotherapy Benefit in Patients With Gastric Cancer. Annals of surgery. 2018; 267(2):311-8.

11. Schliwa M, Woehlke G: Molecular motors. Nature. 2003; 422(6933):759-65.

12. Hirokawa N, Tanaka Y: Kinesin superfamily proteins (KIFs): Various functions and their relevance for important phenomena in life and diseases. Experimental cell research. 2015; 334(1):16-25.

13. Li XL, Ji YM, Song R, Li XN, Guo LS: KIF23 Promotes Gastric Cancer by Stimulating Cell Proliferation. Disease markers. 2019; 2019:9751923.

14. Liu Y, Chen H, Dong P, Xie G, Zhou Y, Ma Y, Yuan X, Yang J, Han L, Chen L et al: KIF23 activated Wnt/beta-catenin signaling pathway through direct interaction with Amer1 in gastric cancer. Aging. 2020; 12(9):8372-96.

15. Hu Y, Zheng M, Wang C, Wang S, Gou R, Liu O, Li X, Liu J, Lin B: Identification of KIF23 as a prognostic signature for ovarian cancer based on large-scale sampling and clinical validation. Am J Transl Res. 2020; 12(9):4955-76.

16. Wei B, Kong W, Mou X, Wang S: Comprehensive analysis of tumor immune infiltration associated with endogenous competitive RNA networks in lung adenocarcinoma. Pathology, research and practice. 2019; 215(1):159-70.

17. Liang WT, Liu XF, Huang HB, Gao ZM, Li K: Prognostic significance of KIF23 expression in gastric cancer. World journal of gastrointestinal oncology. 2020; 12(10):1104-18.

18. Fujimoto A, Totoki Y, Abe T, Boroevich KA, Hosoda F, Nguyen HH, Aoki M, Hosono N, Kubo M, Miya F et al: Wholegenome sequencing of liver cancers identifies etiological influences on mutation patterns and recurrent mutations in chromatin regulators. Nature genetics. 2012; 44(7):760-4.

19. Hoadley KA, Yau C, Hinoue T, Wolf DM, Lazar AJ, Drill E, Shen R, Taylor AM, Cherniack AD, Thorsson V et al: Cell-ofOrigin Patterns Dominate the Molecular Classification of 10,000 Tumors from 33 Types of Cancer. Cell. 2018; 173(2):291-304 e6.

20. Nislow C, Lombillo VA, Kuriyama R, McIntosh JR: A plus-end-directed motor enzyme that moves antiparallel microtubules in vitro localizes to the interzone of mitotic spindles. Nature. 1992; 359(6395):543-7.

21. Davies T, Kodera N, Kaminski Schierle GS, Rees E, Erdelyi M, Kaminski CF, Ando T, Mishima M: CYK4 promotes antiparallel microtubule bundling by optimizing MKLP1 neck conformation. PLoS biology. 2015; 13(4):e1002121.

22. Takahashi S, Fusaki N, Ohta S, Iwahori Y, lizuka Y, Inagawa K, Kawakami Y, Yoshida K, Toda M: Downregulation of KIF23 suppresses glioma proliferation. Journal of neuro-oncology. 2012; 106(3):519-29.

23. Kato T, Lee D, Wu L, Patel P, Young AJ, Wada H, Hu HP, Ujiie H, Kaji M, Kano S et al: Kinesin family members KIF11 and KIF23 as potential therapeutic targets in malignant pleural mesothelioma. International journal of oncology. 2016; 49(2):448-56.

24. Kato T, Wada H, Patel P, Hu HP, Lee D, Ujiie H, Hirohashi K, Nakajima T, Sato M, Kaji M et al: Overexpression of KIF23 predicts clinical outcome in primary lung cancer patients. Lung cancer. 2016; 92:53-61.

25. Iltzsche F, Simon K, Stopp S, Pattschull G, Francke S, Wolter P, Hauser S, Murphy DJ, Garcia P, Rosenwald A et al: An important role for Myb-MuvB and its target gene KIF23 in a mouse model of lung adenocarcinoma. Oncogene. 2017; 36(1):110-21. 
26. Dijksterhuis WPM, Verhoeven RHA, Meijer SL, Slingerland M, Haj Mohammad N, de Vos-Geelen J, Beerepoot LV, van Voorthuizen T, Creemers GJ, van Oijen MGH et al: Increased assessment of HER2 in metastatic gastroesophageal cancer patients: a nationwide population-based cohort study. Gastric cancer : official journal of the International Gastric Cancer Association and the Japanese Gastric Cancer Association. 2020; 23(4):579-90.

27. Zhang $Y$, Wang $X$ : Targeting the Wnt/beta-catenin signaling pathway in cancer. Journal of hematology \& oncology. 2020; 13(1):165.

28. MacDonald BT, Tamai K, He X: Wnt/beta-catenin signaling: components, mechanisms, and diseases. Developmental cell. 2009; 17(1):9-26.

29. Wang B, Tian T, Kalland KH, Ke X, Qu Y: Targeting Wnt/beta-Catenin Signaling for Cancer Immunotherapy. Trends in pharmacological sciences. 2018; 39(7):648-58.

30. Li X, Xiang Y, Li F, Yin C, Li B, Ke X: WNT/beta-Catenin Signaling Pathway Regulating T Cell-Inflammation in the Tumor Microenvironment. Frontiers in immunology. 2019; 10:2293.

31. Koushyar S, Powell AG, Vincan E, Phesse TJ: Targeting Wnt Signaling for the Treatment of Gastric Cancer. Int J Mol Sci. 2020; 21(11).

32. Chen W, Chen X, Li S, Ren B: Expression, immune infiltration and clinical significance of SPAG5 in hepatocellular carcinoma: A gene expression-based study. The journal of gene medicine. 2020; 22(4):e3155.

33. Shu Y, Cheng P: Targeting tumor-associated macrophages for cancer immunotherapy. Biochimica et biophysica acta Reviews on cancer. 2020; 1874(2):188434.

34. Pu Z, Zhu Y, Wang X, Zhong Y, Peng F, Zhang Y: Identification of Prognostic Biomarkers and Correlation With Immune Infiltrates in Hepatocellular Carcinoma Based on a Competing Endogenous RNA Network. Frontiers in genetics. 2021; 12:591623.

35. Anandi P, Tian X, Ito S, Muranski P, Chokshi PD, Watters N, Chawla U, Hensel N, Stroncek DF, Battiwalla M et al: Ex vivo T-cell-depleted allogeneic stem cell transplantation for hematologic malignancies: The search for an optimum transplant T-cell dose and T-cell add-back strategy. Cytotherapy. 2017; 19(6):735-43.

36. Budczies J, Klauschen F, Sinn BV, Gyorffy B, Schmitt WD, Darb-Esfahani S, Denkert C: Cutoff Finder: a comprehensive and straightforward Web application enabling rapid biomarker cutoff optimization. PloS one. 2012; 7(12):e51862.

37. Li B, Severson E, Pignon JC, Zhao H, Li T, Novak J, Jiang P, Shen H, Aster JC, Rodig S et al: Comprehensive analyses of tumor immunity: implications for cancer immunotherapy. Genome biology. 2016; 17(1):174.

38. Aran D, Sirota M, Butte AJ: Systematic pan-cancer analysis of tumour purity. Nat Commun. 2015; 6:8971.

39. Remmele W, Stegner HE: [Recommendation for uniform definition of an immunoreactive score (IRS) for immunohistochemical estrogen receptor detection (ER-ICA) in breast cancer tissue]. Der Pathologe. 1987; 8(3):13840.

40. Halon A, Donizy P, Biecek P, Rudno-Rudzinska J, Kielan W, Matkowski R: HER-2 expression in immunohistochemistry has no prognostic significance in gastric cancer patients. TheScientificWorldJournal. 2012; 2012:941259.

41. Robin X, Turck N, Hainard A, Tiberti N, Lisacek F, Sanchez JC, Muller M: pROC: an open-source package for R and $\mathrm{S}+$ to analyze and compare ROC curves. BMC bioinformatics. 2011; $12: 77$.

42. Liu J, Lichtenberg T, Hoadley KA, Poisson LM, Lazar AJ, Cherniack AD, Kovatich AJ, Benz CC, Levine DA, Lee AV et al: An Integrated TCGA Pan-Cancer Clinical Data Resource to Drive High-Quality Survival Outcome Analytics. Cell. 2018; 173(2):400-16 e11.

\section{Tables}

Page $12 / 24$ 
Table 1. Association between KIF23 expression levels and clinical characteristics in the TCGA-GC cohorts 


\begin{tabular}{|c|c|c|c|}
\hline Characteristic & Low expression of KIF23(n=187) & High expression of KIF23(n=188) & p-value \\
\hline Pathologic T stage, n (\%) & & & 0.756 \\
\hline T1 & $10(2.7 \%)$ & $9(2.5 \%)$ & \\
\hline $\mathrm{T} 2$ & $44(12 \%)$ & $36(9.8 \%)$ & \\
\hline T3 & $84(22.9 \%)$ & $84(22.9 \%)$ & \\
\hline $\mathrm{T} 4$ & $47(12.8 \%)$ & $53(14.4 \%)$ & \\
\hline Pathologic N stage, n (\%) & & & 0.904 \\
\hline No & $58(16.2 \%)$ & $53(14.8 \%)$ & \\
\hline N1 & $48(13.4 \%)$ & $49(13.7 \%)$ & \\
\hline N2 & $35(9.8 \%)$ & $40(11.2 \%)$ & \\
\hline N3 & $37(10.4 \%)$ & $37(10.4 \%)$ & \\
\hline Pathologic M stage, n (\%) & & & 0.626 \\
\hline MO & $161(45.4 \%)$ & $169(47.6 \%)$ & \\
\hline M1 & $14(3.9 \%)$ & $11(3.1 \%)$ & \\
\hline Pathologic stage, n (\%) & & & 0.356 \\
\hline Stage I & $28(8 \%)$ & $25(7.1 \%)$ & \\
\hline Stage II & $59(16.8 \%)$ & $52(14.8 \%)$ & \\
\hline Stage III & 75 (21.3\%) & 75 (21.3\%) & \\
\hline Stage IV & $14(4 \%)$ & $24(6.8 \%)$ & \\
\hline Primary therapy outcome, n (\%) & & & 0.635 \\
\hline PD & $30(9.5 \%)$ & $35(11 \%)$ & \\
\hline SD & $9(2.8 \%)$ & $8(2.5 \%)$ & \\
\hline PR & $1(0.3 \%)$ & $3(0.9 \%)$ & \\
\hline CR & $120(37.9 \%)$ & $111(35 \%)$ & \\
\hline Gender, n (\%) & & & 0.776 \\
\hline Female & $65(17.3 \%)$ & $69(18.4 \%)$ & \\
\hline Male & $122(32.5 \%)$ & 119 (31.7\%) & \\
\hline Age, $\mathrm{n}(\%)$ & & & 0.004 \\
\hline$<=65$ & $96(25.9 \%)$ & $68(18.3 \%)$ & \\
\hline$>65$ & $89(24 \%)$ & $118(31.8 \%)$ & \\
\hline Histological type, n (\%) & & & 0.006 \\
\hline Diffuse Type & $42(11.2 \%)$ & $21(5.6 \%)$ & \\
\hline Mucinous Type & $13(3.5 \%)$ & $6(1.6 \%)$ & \\
\hline
\end{tabular}




\begin{tabular}{|c|c|c|c|}
\hline Characteristic & Low expression of KIF23(n=187) & High expression of KIF23(n=188) & p-value \\
\hline Not Otherwise Specified & $100(26.7 \%)$ & $107(28.6 \%)$ & \\
\hline Papillary Type & $2(0.5 \%)$ & $3(0.8 \%)$ & \\
\hline Signet Ring Type & $6(1.6 \%)$ & $5(1.3 \%)$ & \\
\hline Tubular Type & $24(6.4 \%)$ & $45(12 \%)$ & \\
\hline Residual tumor, n (\%) & & & 0.777 \\
\hline RO & $154(46.8 \%)$ & $144(43.8 \%)$ & \\
\hline R1 & $7(2.1 \%)$ & $8(2.4 \%)$ & \\
\hline $\mathrm{R} 2$ & $7(2.1 \%)$ & $9(2.7 \%)$ & \\
\hline H pylori infection, $\mathrm{n}(\%)$ & & & 0.030 \\
\hline No & $61(37.4 \%)$ & $84(51.5 \%)$ & \\
\hline Yes & $13(8 \%)$ & $5(3.1 \%)$ & \\
\hline Histologic grade, n (\%) & & & 0.129 \\
\hline G1 & $5(1.4 \%)$ & $5(1.4 \%)$ & \\
\hline $\mathrm{G} 2$ & $59(16.1 \%)$ & $78(21.3 \%)$ & \\
\hline G3 & $118(32.2 \%)$ & $101(27.6 \%)$ & \\
\hline
\end{tabular}

Table 2. Correlation between KIF23 and related marker genes of immune cells in TIMER 


\begin{tabular}{|c|c|c|c|c|c|c|c|c|c|}
\hline \multirow[t]{3}{*}{ Description } & \multirow[t]{3}{*}{ Gene markers } & \multicolumn{4}{|l|}{ STAD } & \multicolumn{4}{|l|}{ ESCA } \\
\hline & & \multicolumn{2}{|l|}{ None } & \multicolumn{2}{|l|}{ Purity } & \multicolumn{2}{|l|}{ None } & \multicolumn{2}{|l|}{ Purity } \\
\hline & & Cor & $P$ & Cor & $P$ & Cor & $\mathrm{P}$ & Cor & $\mathrm{P}$ \\
\hline \multirow[t]{2}{*}{ CD8+ T cell } & CD8A & -0.108 & $2.81 \mathrm{e}-02$ & -0.097 & $\begin{array}{l}6.04 \mathrm{e}- \\
02\end{array}$ & -0.113 & $\begin{array}{l}1.26 \mathrm{e}- \\
01\end{array}$ & -0.026 & $\begin{array}{l}7.24 \mathrm{e}- \\
01\end{array}$ \\
\hline & CD8B & 0.036 & $4.62 \mathrm{e}-01$ & 0.055 & $\begin{array}{l}2.84 \mathrm{e}- \\
01\end{array}$ & -0.152 & $\begin{array}{l}3.91 \mathrm{e}^{-} \\
02\end{array}$ & -0.072 & $\begin{array}{l}3.38 \mathrm{e}- \\
01\end{array}$ \\
\hline \multirow[t]{3}{*}{$\begin{array}{l}\text { T cell } \\
\text { (general) }\end{array}$} & CD3D & -0.123 & $1.24 \mathrm{e}-02$ & -0.093 & $\begin{array}{l}7.17 \mathrm{e}- \\
02\end{array}$ & -0.205 & $\begin{array}{l}5.15 e^{-} \\
03\end{array}$ & -0.112 & $\begin{array}{l}1.35 \mathrm{e}- \\
01\end{array}$ \\
\hline & CD3E & -0.138 & $4.96 \mathrm{e}-03$ & -0.105 & $\begin{array}{l}4.12 e- \\
02\end{array}$ & -0.233 & $\begin{array}{l}1.43 e- \\
03\end{array}$ & -0.13 & $\begin{array}{l}8.13 e- \\
02\end{array}$ \\
\hline & CD2 & -0.081 & $9.76 \mathrm{e}-02$ & -0.053 & $\begin{array}{l}3.08 \mathrm{e}- \\
01\end{array}$ & -0.174 & $\begin{array}{l}1.82 \mathrm{e}- \\
02\end{array}$ & -0.072 & $\begin{array}{l}3.37 e- \\
01\end{array}$ \\
\hline \multirow[t]{2}{*}{ B cell } & CD19 & -0.181 & $2.07 e-04$ & -0.168 & $\begin{array}{l}1.03 e- \\
03\end{array}$ & -0.138 & $\begin{array}{l}6.92 \mathrm{e}- \\
02\end{array}$ & -0.032 & $\begin{array}{l}6.67 e- \\
01\end{array}$ \\
\hline & CD79A & -0.29 & $2.06 \mathrm{e}-09$ & -0.276 & $\begin{array}{l}4.59 e- \\
08\end{array}$ & -0.171 & $\begin{array}{l}1.96 \mathrm{e}- \\
02\end{array}$ & -0.084 & $\begin{array}{l}2.63 e- \\
01\end{array}$ \\
\hline \multirow[t]{2}{*}{ Monocyte } & CD86 & -0.028 & $5.68 \mathrm{e}-01$ & 0.005 & $\begin{array}{l}9.30 \mathrm{e}- \\
01\end{array}$ & -0.001 & $\begin{array}{l}9.92 \mathrm{e}- \\
01\end{array}$ & 0.093 & $\begin{array}{l}2.16 \mathrm{e}- \\
01\end{array}$ \\
\hline & $\begin{array}{l}\text { CD115 } \\
\text { (CSF1R) }\end{array}$ & -0.146 & $2.97 e-03$ & -0.136 & $\begin{array}{l}8.21 e- \\
03\end{array}$ & -0.046 & $\begin{array}{l}5.30 e^{-} \\
01\end{array}$ & 0.035 & $\begin{array}{l}6.40 \mathrm{e}- \\
01\end{array}$ \\
\hline \multirow[t]{3}{*}{ TAM } & CCL2 & -0.234 & $1.52 \mathrm{e}-06$ & -0.216 & $\begin{array}{l}2.22 \mathrm{e} \\
05\end{array}$ & 0.051 & $\begin{array}{l}4.88 \mathrm{e}- \\
01\end{array}$ & 0.142 & $\begin{array}{l}5.68 \mathrm{e}- \\
02\end{array}$ \\
\hline & CD68 & -0.002 & $9.67 e-01$ & 0.012 & $\begin{array}{l}8.22 \mathrm{e}- \\
01\end{array}$ & -0.08 & $\begin{array}{l}2.77 \mathrm{e}- \\
01\end{array}$ & -0.05 & $\begin{array}{l}5.02 \mathrm{e}- \\
01\end{array}$ \\
\hline & IL10 & -0.013 & $7.90 \mathrm{e}-01$ & 0.013 & $\begin{array}{l}7.89 \mathrm{e}- \\
01\end{array}$ & -0.001 & $\begin{array}{l}9.94 \mathrm{e}- \\
01\end{array}$ & 0.073 & $\begin{array}{l}3.32 \mathrm{e}- \\
01\end{array}$ \\
\hline \multirow[t]{3}{*}{$\begin{array}{l}\text { M1 } \\
\text { Macrophage }\end{array}$} & INOS (NOS2) & 0.178 & $2.62 \mathrm{e}-04$ & 0.18 & $\begin{array}{l}4.38 e- \\
04\end{array}$ & -0.12 & $\begin{array}{l}1.03 e- \\
01\end{array}$ & -0.139 & $\begin{array}{l}6.26 \mathrm{e}- \\
02\end{array}$ \\
\hline & IRF5 & 0.003 & $9.49 \mathrm{e}-01$ & 0.016 & $\begin{array}{l}7.52 \mathrm{e}- \\
01\end{array}$ & -0.098 & $\begin{array}{l}1.85 \mathrm{e}- \\
01\end{array}$ & -0.069 & $\begin{array}{l}3.56 \mathrm{e}- \\
01\end{array}$ \\
\hline & COX2(PTGS2) & 0.032 & $5.19 e-01$ & 0.039 & $\begin{array}{l}4.46 \mathrm{e}- \\
01\end{array}$ & 0.219 & $\begin{array}{l}2.77 e- \\
03\end{array}$ & 0.246 & $\begin{array}{l}8.52 \mathrm{e}- \\
04\end{array}$ \\
\hline \multirow[t]{3}{*}{$\begin{array}{l}\text { M2 } \\
\text { Macrophage }\end{array}$} & CD163 & 0.029 & $5.61 \mathrm{e}-01$ & 0.044 & $\begin{array}{l}3.97 \mathrm{e}- \\
01\end{array}$ & -0.084 & $\begin{array}{l}2.55 \mathrm{e}- \\
01\end{array}$ & -0.009 & $\begin{array}{l}9.00 \mathrm{e}- \\
01\end{array}$ \\
\hline & VSIG4 & -0.093 & $5.86 \mathrm{e}-02$ & -0.08 & $\begin{array}{l}1.20 \mathrm{e}- \\
01\end{array}$ & -0.039 & $\begin{array}{l}5.95 \mathrm{e}- \\
01\end{array}$ & 0.037 & $\begin{array}{l}6.18 \mathrm{e}- \\
01\end{array}$ \\
\hline & MS4A4A & -0.145 & $3.04 \mathrm{e}-03$ & -0.127 & $\begin{array}{l}1.35 e- \\
02\end{array}$ & -0.075 & $\begin{array}{l}3.08 \mathrm{e}- \\
01\end{array}$ & 0.014 & $\begin{array}{l}8.35 \mathrm{e}- \\
01\end{array}$ \\
\hline Neutrophils & $\begin{array}{l}\text { CD66b } \\
\text { (CEACAM8) }\end{array}$ & 0.169 & $5.26 \mathrm{e}-04$ & 0.175 & $\begin{array}{l}6.16 e- \\
04\end{array}$ & -0.093 & $\begin{array}{l}2.07 e- \\
01\end{array}$ & -0.048 & $\begin{array}{l}5.21 \mathrm{e}^{-} \\
01\end{array}$ \\
\hline C & $\begin{array}{l}\text { CD11b } \\
\text { (ITGAM) }\end{array}$ & $\begin{array}{l}- \\
-0.109\end{array}$ & $\begin{array}{l}22.71 e^{-} \\
02\end{array}$ & -0.091 & & $\begin{array}{l}- \\
-0.062\end{array}$ & $\begin{array}{l}24.04 \mathrm{e}- \\
01\end{array}$ & -0.006 & \\
\hline
\end{tabular}




\begin{tabular}{|c|c|c|c|c|c|c|c|c|c|}
\hline & & & & & $\begin{array}{l}7.83 e- \\
02\end{array}$ & & & & $\begin{array}{l}9.41 \mathrm{e}^{-} \\
01\end{array}$ \\
\hline C & CCR7 & $\begin{array}{l}- \\
-0.258\end{array}$ & $1.14 \mathrm{e}-07$ & $\begin{array}{l}- \\
-0.232\end{array}$ & $\begin{array}{l}55.02 e- \\
06\end{array}$ & $\begin{array}{l}- \\
-0.244\end{array}$ & $\begin{array}{l}7.98 \mathrm{e}- \\
04\end{array}$ & $\begin{array}{l}- \\
-0.144\end{array}$ & $\begin{array}{l}55.38 \mathrm{e}- \\
02\end{array}$ \\
\hline \multirow[t]{7}{*}{$\begin{array}{l}\text { Natural killer } \\
\text { cells }\end{array}$} & KIR2DL1 & 0.102 & $3.79 e-02$ & 0.118 & $\begin{array}{l}2.11 e- \\
02\end{array}$ & -0.089 & $\begin{array}{l}2.28 \mathrm{e}- \\
01\end{array}$ & -0.026 & $\begin{array}{l}7.29 \mathrm{e}- \\
01\end{array}$ \\
\hline & KIR2DL3 & 0.104 & $3.47 e-02$ & 0.121 & $\begin{array}{l}1.81 e- \\
02\end{array}$ & -0.081 & $\begin{array}{l}2.72 \mathrm{e}- \\
01\end{array}$ & -0.055 & $\begin{array}{l}4.67 e- \\
01\end{array}$ \\
\hline & KIR2DL4 & 0.185 & $1.54 \mathrm{e}-04$ & 0.213 & $\begin{array}{l}2.95 e- \\
05\end{array}$ & -0.089 & $\begin{array}{l}2.27 e^{-} \\
01\end{array}$ & -0.035 & $\begin{array}{l}6.41 \mathrm{e}- \\
01\end{array}$ \\
\hline & KIR3DL1 & 0.024 & $6.24 \mathrm{e}-01$ & 0.013 & $\begin{array}{l}8.02 \mathrm{e}- \\
01\end{array}$ & -0.128 & $\begin{array}{l}8.29 \mathrm{e}- \\
02\end{array}$ & -0.069 & $\begin{array}{l}3.57 e- \\
01\end{array}$ \\
\hline & KIR3DL2 & 0.05 & $3.13 e-01$ & 0.068 & $\begin{array}{l}1.88 \mathrm{e}- \\
01\end{array}$ & -0.042 & $\begin{array}{l}5.70 e^{-} \\
01\end{array}$ & 0.018 & $\begin{array}{l}8.08 \mathrm{e}- \\
01\end{array}$ \\
\hline & KIR3DL3 & 0.122 & $1.27 \mathrm{e}-02$ & 0.126 & $\begin{array}{l}1.38 e- \\
02\end{array}$ & -0.087 & $\begin{array}{l}2.40 \mathrm{e}- \\
01\end{array}$ & -0.097 & $\begin{array}{l}1.97 e- \\
01\end{array}$ \\
\hline & KIR2DS4 & 0.055 & $2.60 \mathrm{e}-01$ & 0.068 & $\begin{array}{l}1.86 \mathrm{e}^{-} \\
01\end{array}$ & -0.01 & $\begin{array}{l}8.95 \mathrm{e}- \\
01\end{array}$ & -0.007 & $\begin{array}{l}9.21 \mathrm{e}- \\
01\end{array}$ \\
\hline \multirow[t]{7}{*}{ Dendritic cell } & HLA-DPB1 & -0.205 & $2.79 \mathrm{e}-05$ & -0.18 & $\begin{array}{l}4.16 e- \\
04\end{array}$ & -0.232 & $\begin{array}{l}1.48 e^{-} \\
03\end{array}$ & -0.15 & $\begin{array}{l}4.41 e- \\
02\end{array}$ \\
\hline & HLA-DQB1 & -0.119 & $1.50 \mathrm{e}-02$ & -0.085 & $\begin{array}{l}9.65 \mathrm{e}- \\
02\end{array}$ & -0.212 & $\begin{array}{l}3.71 \mathrm{e}- \\
03\end{array}$ & -0.135 & $\begin{array}{l}7.04 \mathrm{e}- \\
02\end{array}$ \\
\hline & HLA-DRA & -0.099 & $4.49 e-02$ & -0.069 & $\begin{array}{l}1.79 \mathrm{e}- \\
01\end{array}$ & -0.191 & $\begin{array}{l}9.36 \mathrm{e}^{-} \\
03\end{array}$ & -0.108 & $\begin{array}{l}1.49 \mathrm{e}- \\
01\end{array}$ \\
\hline & HLA-DPA1 & -0.127 & $9.83 e-03$ & -0.1 & $\begin{array}{l}5.15 e^{-} \\
02\end{array}$ & -0.181 & $\begin{array}{l}1.37 e- \\
02\end{array}$ & -0.109 & $\begin{array}{l}1.45 \mathrm{e}- \\
01\end{array}$ \\
\hline & BDCA-1(CD1C) & -0.381 & $9.42 \mathrm{e}-16$ & -0.375 & $\begin{array}{l}3.97 e- \\
14\end{array}$ & -0.185 & $\begin{array}{l}1.15 e^{-} \\
02\end{array}$ & -0.098 & $\begin{array}{l}1.90 \mathrm{e}- \\
01\end{array}$ \\
\hline & BDCA-4(NRP1) & -0.312 & $1.03 e-10$ & -0.3 & $\begin{array}{l}2.69 e- \\
09\end{array}$ & 0.128 & $\begin{array}{l}8.20 \mathrm{e}- \\
02\end{array}$ & 0.212 & $\begin{array}{l}4.26 e- \\
03\end{array}$ \\
\hline & $\begin{array}{l}\text { CD11c } \\
(\text { ITGAX) }\end{array}$ & -0.013 & 7.95e-01 & 0.025 & $\begin{array}{l}6.21 \mathrm{e}- \\
01\end{array}$ & -0.109 & $\begin{array}{l}1.38 \mathrm{e}^{-} \\
01\end{array}$ & 0.006 & $\begin{array}{l}9.36 \mathrm{e}- \\
01\end{array}$ \\
\hline \multirow[t]{5}{*}{ Th1 } & T-bet (TBX21) & -0.062 & $2.11 \mathrm{e}-01$ & -0.041 & $\begin{array}{l}4.23 e- \\
01\end{array}$ & -0.152 & $\begin{array}{l}3.83 e- \\
02\end{array}$ & -0.041 & $\begin{array}{l}5.82 \mathrm{e}- \\
01\end{array}$ \\
\hline & STAT4 & -0.046 & $3.45 e-01$ & -0.024 & $\begin{array}{l}6.44 \mathrm{e}- \\
01\end{array}$ & -0.125 & $\begin{array}{l}8.90 \mathrm{e}- \\
02\end{array}$ & 0 & $\begin{array}{l}9.98 \mathrm{e}- \\
01\end{array}$ \\
\hline & STAT1 & 0.4 & $0.00 e+00$ & 0.402 & $\begin{array}{l}3.51 e- \\
16\end{array}$ & 0.179 & $\begin{array}{l}1.50 \mathrm{e}- \\
02\end{array}$ & 0.248 & $\begin{array}{l}8.04 \mathrm{e} \\
04\end{array}$ \\
\hline & IFN-y (IFNG) & 0.211 & $1.39 \mathrm{e}-05$ & 0.23 & $\begin{array}{l}6.28 e- \\
06\end{array}$ & 0.003 & $\begin{array}{l}9.66 \mathrm{e}- \\
01\end{array}$ & 0.084 & $\begin{array}{l}2.60 \mathrm{e}- \\
01\end{array}$ \\
\hline & TNF-a (TNF) & 0.084 & $8.93 e-02$ & 0.115 & $\begin{array}{l}2.56 \mathrm{e}- \\
02\end{array}$ & 0.134 & $\begin{array}{l}6.99 \mathrm{e}- \\
02\end{array}$ & 0.184 & $\begin{array}{l}1.34 \mathrm{e}- \\
02\end{array}$ \\
\hline Th2 & GATA3 & -0.189 & $1.11 \mathrm{e}-04$ & -0.166 & $\begin{array}{l}1.14 \mathrm{e}- \\
03\end{array}$ & 0.006 & $\begin{array}{l}9.40 \mathrm{e}- \\
01\end{array}$ & 0.075 & $\begin{array}{l}3.16 e- \\
01\end{array}$ \\
\hline
\end{tabular}




\begin{tabular}{|c|c|c|c|c|c|c|c|c|c|}
\hline & STAT6 & 0.036 & $4.71 \mathrm{e}-01$ & 0.025 & $\begin{array}{l}6.30 \mathrm{e}- \\
01\end{array}$ & 0.115 & $\begin{array}{l}1.20 \mathrm{e}- \\
01\end{array}$ & 0.111 & $\begin{array}{l}1.36 \mathrm{e}- \\
01\end{array}$ \\
\hline & STAT5A & 0.002 & $9.64 \mathrm{e}-01$ & 0.022 & $\begin{array}{l}6.76 \mathrm{e}- \\
01\end{array}$ & -0.008 & $\begin{array}{l}9.13 e- \\
01\end{array}$ & 0.053 & $\begin{array}{l}4.76 \mathrm{e}- \\
01\end{array}$ \\
\hline & IL13 & -0.007 & $8.84 \mathrm{e}-01$ & 0.003 & $\begin{array}{l}9.61 \mathrm{e}^{-} \\
01\end{array}$ & -0.059 & $\begin{array}{l}4.22 \mathrm{e}- \\
01\end{array}$ & 0.003 & $\begin{array}{l}9.73 e- \\
01 .\end{array}$ \\
\hline \multirow[t]{2}{*}{ Tfh } & BCL6 & -0.197 & $5.36 \mathrm{e}-05$ & -0.186 & $\begin{array}{l}2.71 e- \\
04\end{array}$ & 0.19 & $\begin{array}{l}9.51 \mathrm{e}^{-} \\
03\end{array}$ & 0.189 & $\begin{array}{l}1.11 \mathrm{e}- \\
02\end{array}$ \\
\hline & IL21 & 0.146 & $2.80 \mathrm{e}-03$ & 0.181 & $\begin{array}{l}3.91 \mathrm{e} \\
04\end{array}$ & -0.049 & $5.1 \mathrm{e}-01$ & -0.001 & $\begin{array}{l}9.89 \mathrm{e}- \\
01\end{array}$ \\
\hline \multirow[t]{2}{*}{ Th17 } & STAT3 & 0.075 & $1.28 \mathrm{e}-01$ & 0.077 & $\begin{array}{l}1.33 e- \\
01\end{array}$ & 0.196 & $\begin{array}{l}5.73 e- \\
03\end{array}$ & 0.234 & $\begin{array}{l}1.54 \mathrm{e} \\
03\end{array}$ \\
\hline & IL17A & 0.194 & $6.78 \mathrm{e}-05$ & 0.21 & $\begin{array}{l}3.73 e- \\
05\end{array}$ & -0.071 & $\begin{array}{l}3.35 \mathrm{e}- \\
01\end{array}$ & -0.056 & $\begin{array}{l}4.55 e- \\
01\end{array}$ \\
\hline \multirow[t]{4}{*}{ Treg } & FOXP3 & 0.067 & $1.75 \mathrm{e}-01$ & 0.095 & $\begin{array}{l}6.41 \mathrm{e}^{-} \\
02\end{array}$ & 0.024 & $\begin{array}{l}7.48 \mathrm{e}- \\
01\end{array}$ & 0.115 & $\begin{array}{l}1.24 \mathrm{e}- \\
01\end{array}$ \\
\hline & CCR8 & 0.067 & $1.73 e-01$ & 0.081 & $\begin{array}{l}1.14 \mathrm{e}- \\
01\end{array}$ & -0.01 & $\begin{array}{l}8.92 \mathrm{e}- \\
01\end{array}$ & 0.084 & $\begin{array}{l}2.63 \mathrm{e}- \\
01\end{array}$ \\
\hline & STAT5B & -0.032 & $5.14 \mathrm{e}-01$ & -0.022 & $\begin{array}{l}6.75 \mathrm{e}- \\
01\end{array}$ & 0.17 & $\begin{array}{l}2.06 \mathrm{e}- \\
02\end{array}$ & 0.171 & $\begin{array}{l}2.14 \mathrm{e}- \\
02\end{array}$ \\
\hline & TGR $\beta$ (TGFB1) & -0.161 & $1.02 \mathrm{e}-03$ & -0.142 & $\begin{array}{l}5.45 e- \\
03\end{array}$ & 0.105 & $\begin{array}{l}1.54 \mathrm{e}- \\
01\end{array}$ & 0.156 & $\begin{array}{l}3.63 e- \\
02\end{array}$ \\
\hline \multirow[t]{5}{*}{$\begin{array}{l}\text { T cell } \\
\text { exhaustion }\end{array}$} & PD-1(PDCD1) & 0.007 & $8.86 e-01$ & 0.036 & $\begin{array}{l}4.81 \mathrm{e}- \\
01\end{array}$ & -0.013 & $\begin{array}{l}8.61 \mathrm{e}- \\
01\end{array}$ & -0.101 & $1.7 e-01$ \\
\hline & CTLA4 & 0.182 & $2.02 \mathrm{e}-04$ & 0.219 & $\begin{array}{l}1.72 e- \\
05\end{array}$ & 0.075 & $\begin{array}{l}3.15 \mathrm{e}- \\
01\end{array}$ & -0.028 & $\begin{array}{l}7.06 \mathrm{e} \\
01\end{array}$ \\
\hline & LAG3 & 0.071 & $1.47 e-01$ & 0.086 & $\begin{array}{l}9.52 \mathrm{e}- \\
02\end{array}$ & 0.077 & $\begin{array}{l}3.04 \mathrm{e}- \\
01\end{array}$ & -0.008 & $\begin{array}{l}9.11 \mathrm{e}- \\
01\end{array}$ \\
\hline & $\begin{array}{l}\text { TIM- } \\
\text { 3(HAVCR2) }\end{array}$ & 0.016 & $7.48 \mathrm{e}-01$ & 0.039 & $\begin{array}{l}4.52 \mathrm{e}- \\
01\end{array}$ & 0.075 & $\begin{array}{l}3.19 \mathrm{e}- \\
01\end{array}$ & -0.021 & $\begin{array}{l}7.82 \mathrm{e}- \\
01\end{array}$ \\
\hline & GZMB & 0.169 & $5.76 e-04$ & 0.201 & $\begin{array}{l}8.36 \mathrm{e} \\
05\end{array}$ & 0.02 & $\begin{array}{l}7.85 \mathrm{e}^{-} \\
01\end{array}$ & -0.07 & $\begin{array}{l}3.44 \mathrm{e}- \\
01\end{array}$ \\
\hline
\end{tabular}

STAD: stomach adenocarcinoma; ESCA: esophageal carcinoma; tumor-associated macrophage; Th, T helper cell; Tfh, Follicular helper T cell; Treg, regulatory T cell; Cor, R value of Spearman's correlation; None, correlation without adjustment. Purity, correlation adjusted by purity. ${ }^{*} \mathrm{P}<0.01$; ${ }^{\star \star} \mathrm{P}<0.001$; $* \star \star \mathrm{P}<0.0001$.

Table 3. Correlation between KIF23 and related marker genes of immune cells in GEPIA. 


\begin{tabular}{|c|c|c|c|c|c|c|c|c|c|}
\hline \multirow[t]{3}{*}{ Description } & \multirow[t]{3}{*}{ Gene markers } & \multicolumn{4}{|l|}{ STAD } & \multicolumn{4}{|l|}{ ESCA } \\
\hline & & \multicolumn{2}{|l|}{ Tumor } & \multicolumn{2}{|l|}{ Normal } & \multicolumn{2}{|l|}{ Tumor } & \multicolumn{2}{|l|}{ Normal } \\
\hline & & $\mathrm{R}$ & $\mathrm{P}$ & $\mathrm{R}$ & $P$ & $\mathrm{R}$ & $P$ & $\mathrm{R}$ & $\mathrm{P}$ \\
\hline Monocyte & $\begin{array}{l}\text { CD115 } \\
\text { (CSF1R) }\end{array}$ & -0.12 & 0.016 & 0.0094 & 0.96 & -0.034 & 0.65 & 0.0055 & 0.99 \\
\hline TAM & CCL2 & -0.23 & $3.9 \mathrm{e}-06$ & -0.51 & 0.0014 & 0.056 & 0.46 & 0.099 & 0.75 \\
\hline \multirow[t]{2}{*}{ Neutrophils } & CD66b & 0.12 & 0.012 & -0.19 & 0.28 & -0.013 & 0.86 & 0.31 & 0.3 \\
\hline & CCR7 & -0.26 & $1.3 e-07$ & 0.49 & 0.0027 & -0.24 & 0.0011 & 0.37 & 0.21 \\
\hline \multirow{4}{*}{$\begin{array}{l}\text { Natural } \\
\text { killer cell }\end{array}$} & KIR2DL1 & 0.00057 & 0.99 & 0.066 & 0.7 & -0.1 & 0.17 & 0.29 & 0.34 \\
\hline & KIR2DL3 & 0.054 & 0.27 & 0.2 & 0.24 & -0.057 & 0.45 & 0.33 & 0.27 \\
\hline & KIR2DL4 & 0.16 & 0.0016 & 0.29 & 0.089 & -0.069 & 0.36 & -0.11 & 0.71 \\
\hline & KIR3DL3 & 0.073 & 0.14 & -0.025 & 0.88 & -0.096 & 0.2 & 0.46 & 0.11 \\
\hline \multirow{3}{*}{$\begin{array}{l}\text { Dendritic } \\
\text { cell }\end{array}$} & HLA-DPB1 & -0.19 & 0.00011 & 0.15 & 0.37 & -0.19 & 0.0094 & 0.22 & 0.47 \\
\hline & $\begin{array}{l}\text { BDCA- } \\
1 \text { (CD1C) }\end{array}$ & -0.38 & $3.1 \mathrm{e}-15$ & 0.16 & 0.35 & -0.19 & 0.0096 & 0.3 & 0.32 \\
\hline & $\begin{array}{l}\text { BDCA- } \\
4(\text { NRP1) }\end{array}$ & -0.037 & 0.45 & -0.56 & 0.00035 & 0.15 & 0.045 & 0.2 & 0.5 \\
\hline \multirow[t]{3}{*}{ Th1 } & STAT1 & 0.4 & $1.8 \mathrm{e}-17$ & 0.15 & 0.38 & 0.22 & 0.0029 & 0.71 & 0.0081 \\
\hline & IFN-Y (IFNG) & 0.19 & $8 e-05$ & 0.16 & 0.35 & 0.017 & 0.82 & 0.16 & 0.6 \\
\hline & TNF-a (TNF) & 0.099 & 0.046 & 0.34 & 0.039 & 0.16 & 0.03 & 0.51 & 0.078 \\
\hline Th2 & GATA3 & -0.16 & 0.0014 & 0.45 & 0.0061 & 0.016 & 0.83 & 0.54 & 0.059 \\
\hline \multirow[t]{2}{*}{ Tfh } & BCL6 & -0.1 & 0.038 & -0.18 & 0.3 & 0.19 & 0.01 & 0.31 & 0.3 \\
\hline & IL21 & 0.067 & 0.18 & 0.3 & 0.076 & -0.14 & 0.069 & 0.38 & 0.21 \\
\hline Th17 & IL17A & 0.19 & $8.1 \mathrm{e}-05$ & 0.44 & 0.0072 & -0.056 & 0.45 & 0.7 & 0.0079 \\
\hline Treg & TGF $\beta($ TGFB1) & -0.13 & 0.0087 & 0.22 & 0.19 & 0.12 & 0.11 & 0.35 & 0.25 \\
\hline \multirow{2}{*}{$\begin{array}{l}\mathrm{T} \text { cell } \\
\text { exhaustion }\end{array}$} & CTLA-4 & 0.16 & 0.00084 & 0.38 & 0.021 & -0.012 & 0.87 & 0.57 & 0.041 \\
\hline & GZMB & 0.16 & 0.0015 & 0.25 & 0.14 & -0.039 & 0.6 & 0.16 & 0.59 \\
\hline
\end{tabular}

\section{Figures}



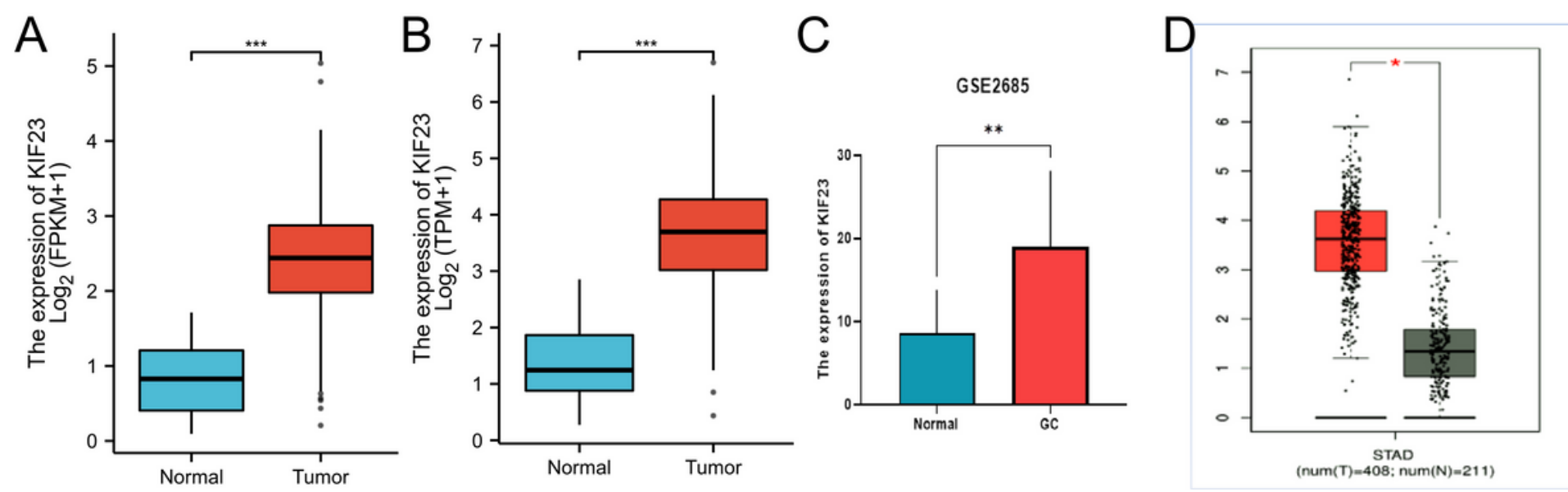

Figure 1

The mRNA level of KIF23 expression in GC patients. (A) The mRNA level of KIF23 expression in GC patients and normal patients in TCGA database. (B)The expression of KIF23 in paired GC by TCGA data. (C) KIF23 expression in tumors was higher than that in normal tissue in GEO database. (D) The mRNA level of KIF23 expression in GC patients and normal patients in GEPIA database. Red stands for increased expression; blue stands for decreased expression. * $p<0.05$, ${ }^{* *} p<0.01,{ }^{* * *} p<0.001$.
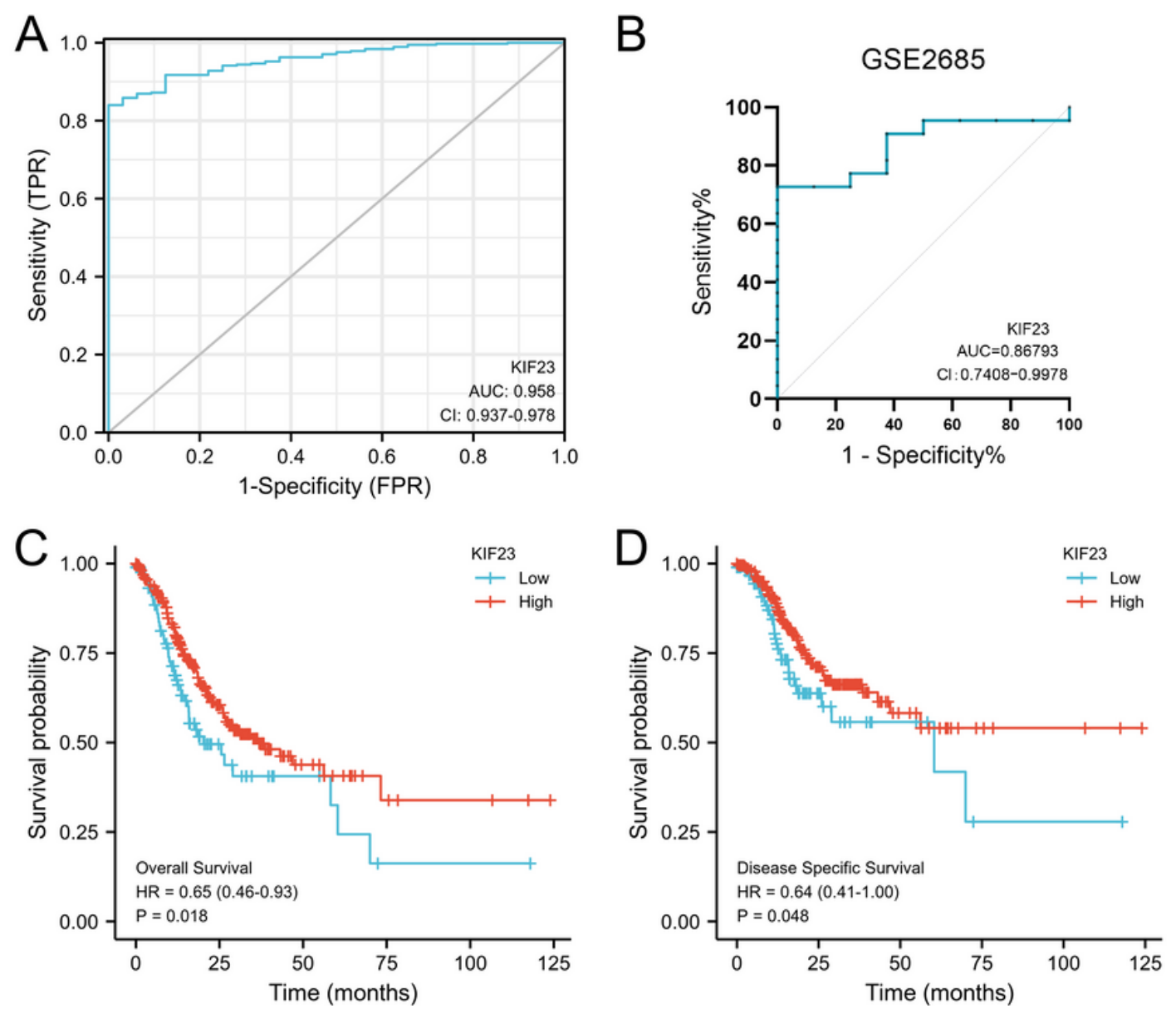

Figure 2 
Diagnostic and prognostic value of KIF23 in gastric cancer. (A) ROC curves for GC patients in TCGA datasets. (B) ROC curves for GC patients in GEO datasets. (C-D) OS and PFS survival curves of GC patients in TCGA datasets.

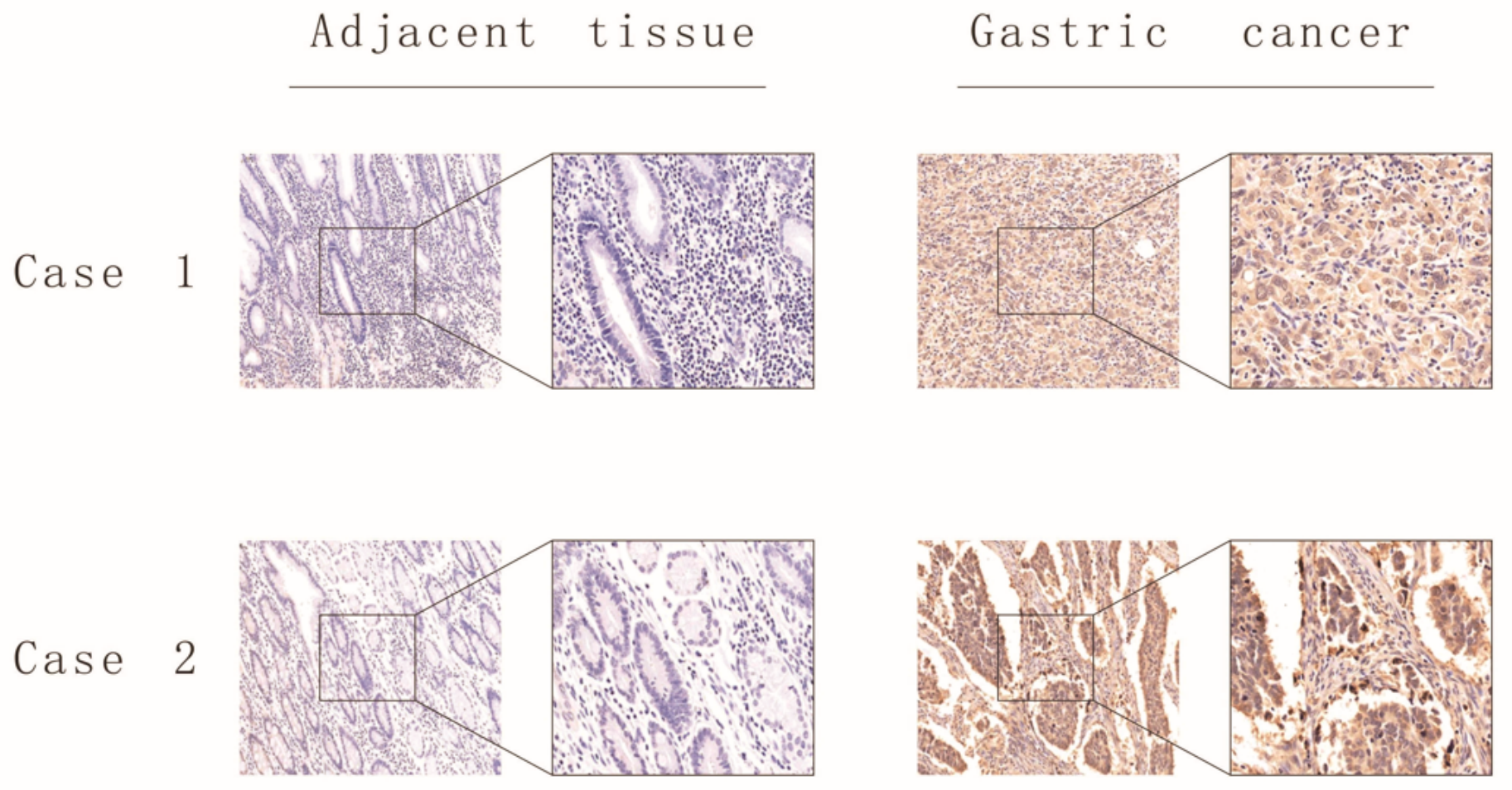

Figure 3

Immunohistochemical results showed the expression levels of KIF23 in adjacent gastric tissues and stomach adenocarcinoma tissues. Magnification, $\times 200: \times 400$.

\section{Figure 4}

KIF23 mutations in GC. (A) The schematic representation of KIF23 mutations in GC (cBioPortal). (B-C) The mutation types of AGRN (\%) in GC the Catalogue of Somatic Mutations in Cancer (COSMIC) database

\section{Figure 5}

Co-expressed genes and Protein-protein Interaction (PPI) Network analysis of KIF23 (LinkedOmics). (A) Correlations between KIF23 and differentially expressed genes in GC. (B and C) Heatmaps indicate the top 50 genes positively and negatively correlated withKIF23 in GC. Red refers to positively correlated genes and green refers to negatively correlated genes. Statistical analysis was performed using Pearson's test. (D) The PPI network of hub-genes were identified using STRING database. E The interaction network of the top 10 hub genes. (F) Protein-protein interaction network of KIF23 analyzed by GeneMANIA.

\section{Figure 6}


Potential mechanisms of KIF23 in GC. (A) Barplot graph for GO enrichment. (B) Bubble graph for KEGG pathway. (C) GO biological process terms and (D) KEGG pathways significantly enriched in genes coexpressed with KIF23 in the GC cohort.

\section{A}

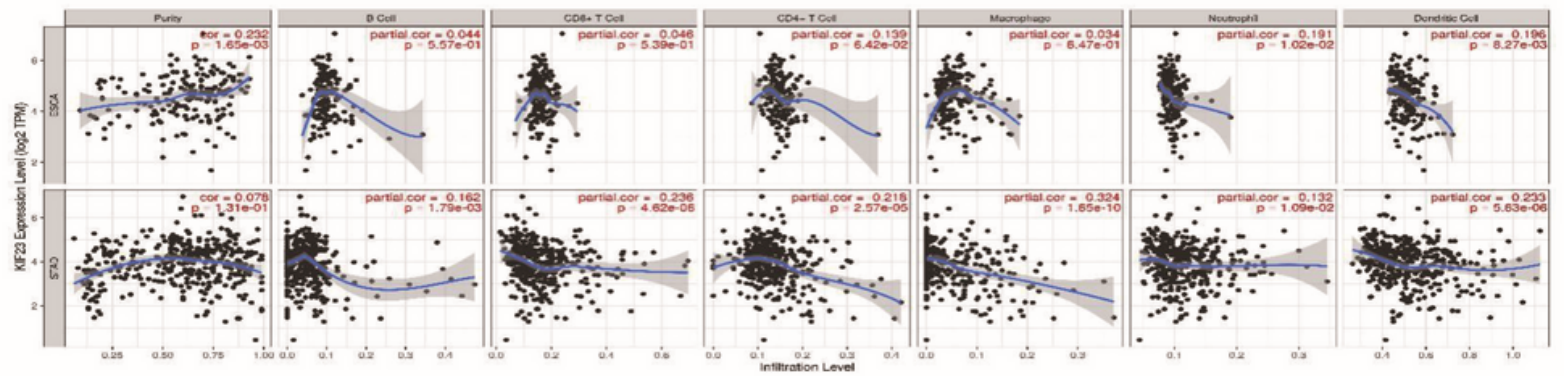

B
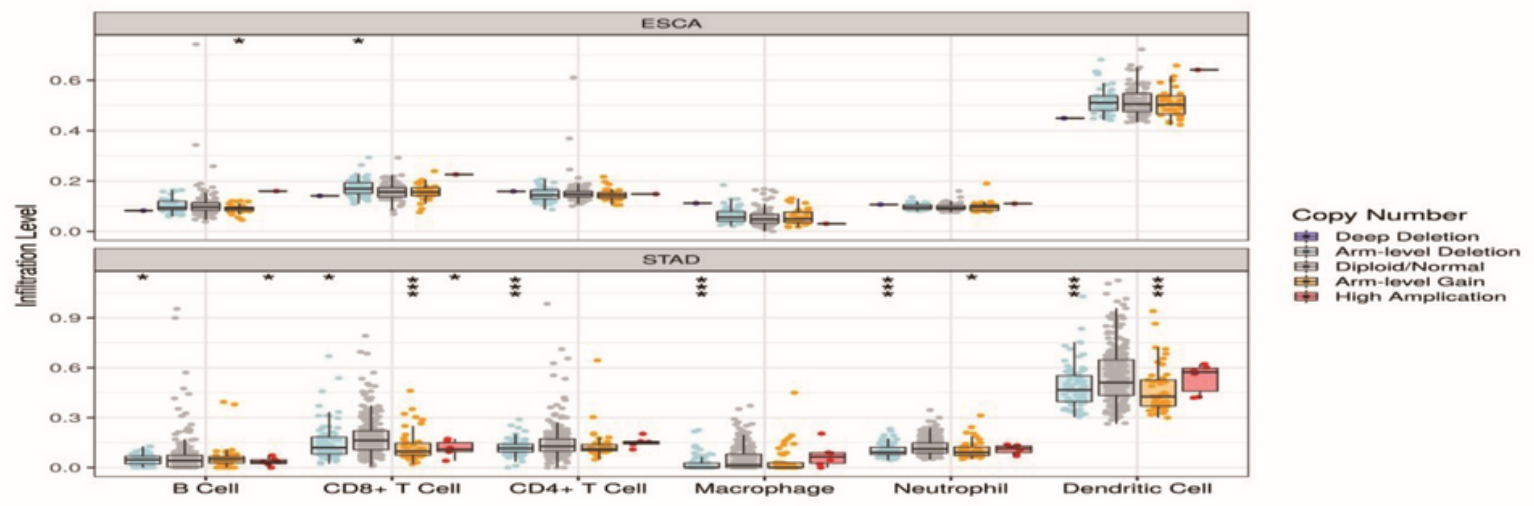

Figure 7

Correlations of KIF23 expression with immune infiltration in STAD (stomach adenocarcinoma) and ESCA (esophageal carcinoma). (A) KIF23 expression is positively with tumor purity, and negatively with the infiltration of $B$ cells, CD8+ T cells, CD4+ T cells, macrophages, neutrophils, and dendritic cells in GC $(n=457)$ and in ESCA( $n=184)$. (B) Tumor infiltration levels in STAD and ESCA with different SCNAs in KIF23. SCNAs are defined by GISTIC 2.0, including deep deletion (-2), arm-level deletion (-1), diploid/normal (0), arm-level gain (1), and high amplification (2). P-value Significant Codes: $0 \leq \leq^{\star \star *}<.001 \leq^{* *}<.01 \leq *<.05 \leq .<.1$. 

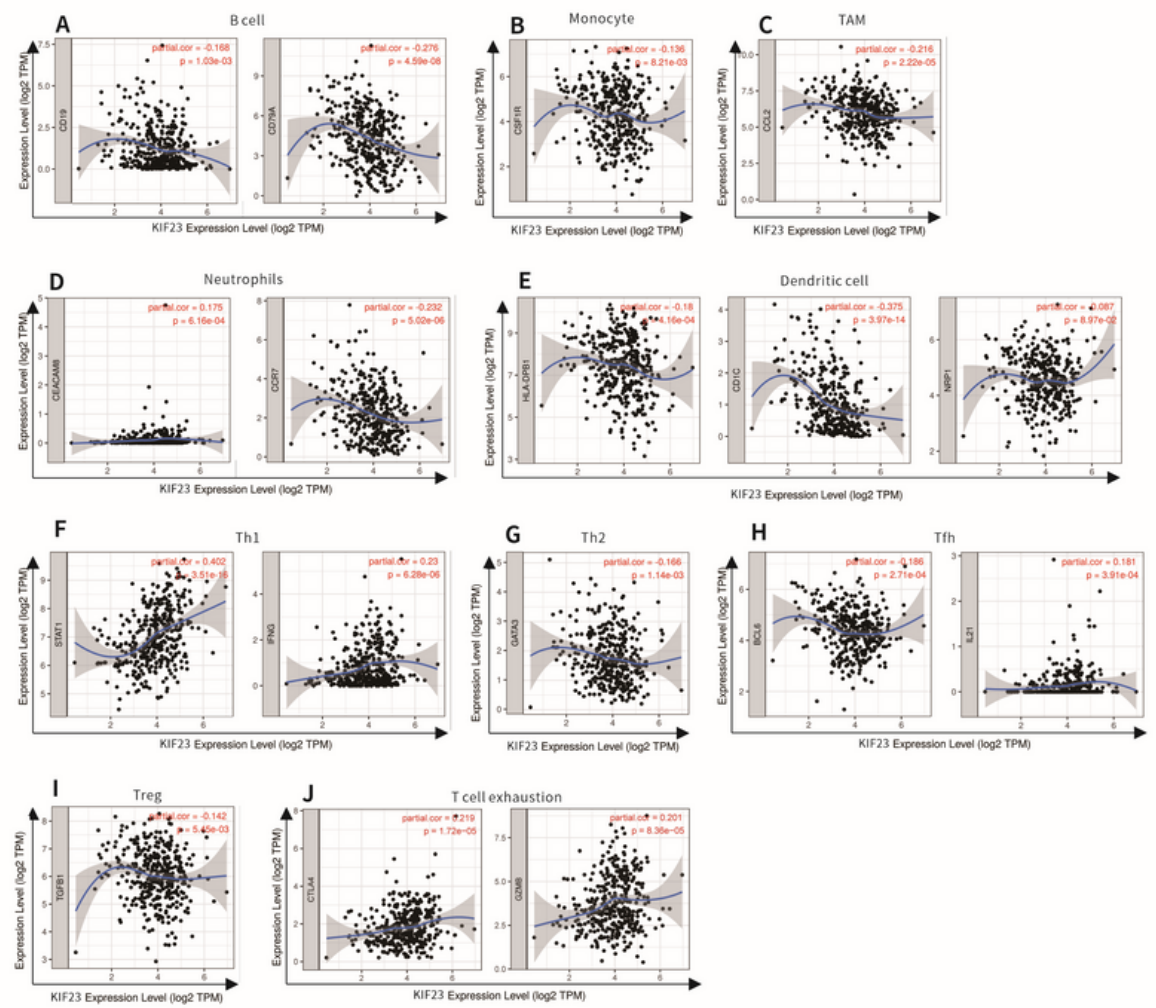

\section{Figure 8}

Correlation between KIF23 expression and the expression of marker genes of infiltrating immune cells in STAD using TIMER database. 

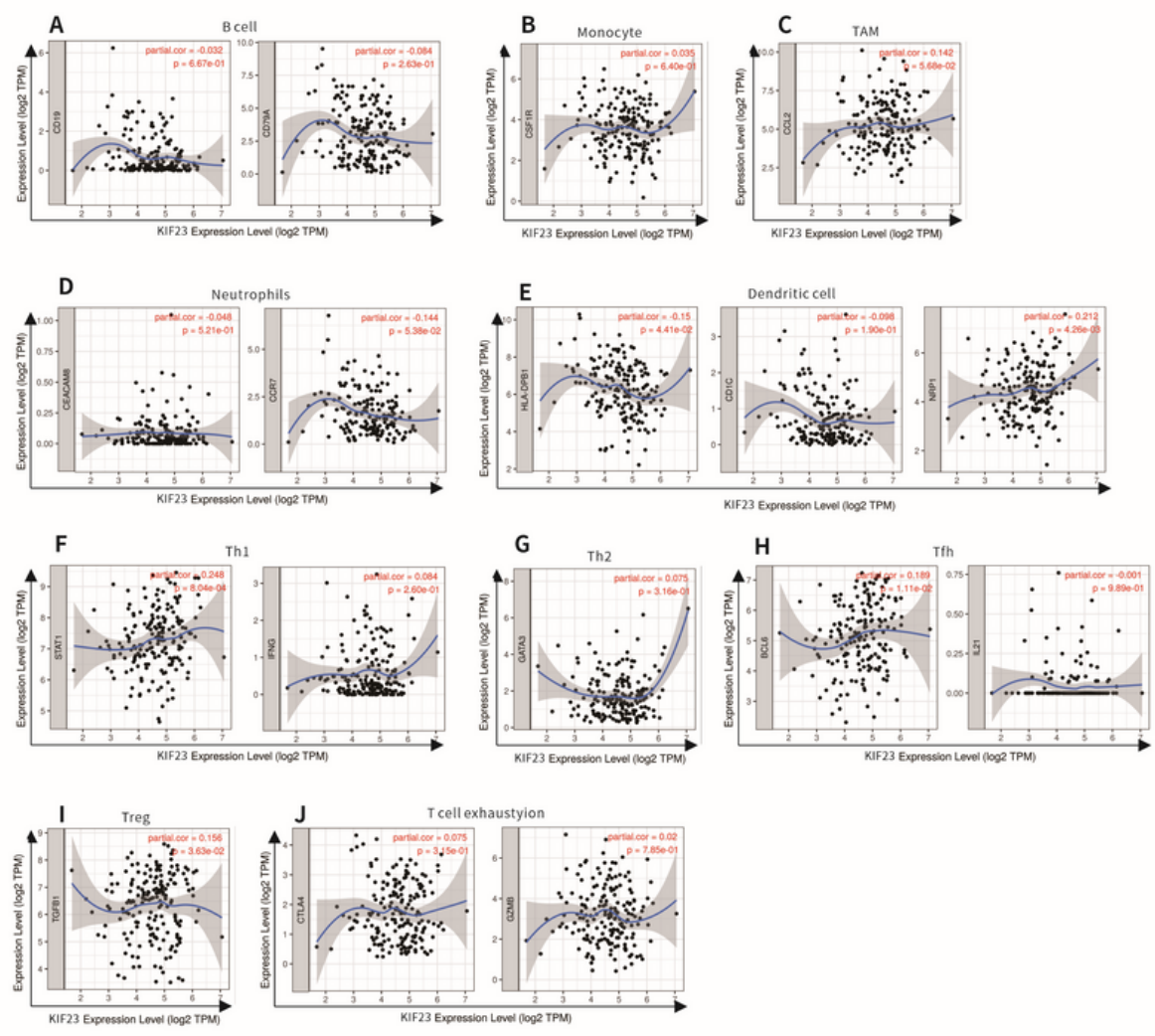

\section{Figure 9}

Correlation between KIF23 expression and the expression of marker genes of infiltrating immune cells in ESCA using TIMER database.

\section{Supplementary Files}

This is a list of supplementary files associated with this preprint. Click to download.

- SupplementaryFigureS1.png

- SupplementaryFigureS2.docx 